\title{
Magnitude and Factors Associated with Optimal Complementary Feeding Practices among Children Aged 6-23 Months in Bensa District, Sidama Zone, South Ethiopia
}

\author{
Muntasha Birhanu $^{1 *}$,Teferi Abegaz ${ }^{2}$, Rekiku Fikre ${ }^{3}$
}

\footnotetext{
OPEN ACCESS

Citation: Muntasha Birhanu, Teferi Abegaz, Rekiku Fikre. Magnitude and factors associated with optimal complementary feeding practices among children aged 6-23 months in bensa district, Sidama zone south Ethiopia, 2016. Ethiop J Health Sci.2017;29(2):153.

doi:http://dx.doi.org/10.4314/ejhs.v29i2.2 Received: December 2, 2017

Accepted: July 6, 2017

Published: March 1, 2019

Copyright: (c) 2018 Muntasha Birhanu, et al. This is an open access article distributed under the terms of the Creative Commons Attribution License, which permits unrestricted use, distribution, and reproduction in any medium, provided the original author and source are credited.

Funding: Nil

Competing Interests: The authors declare that this manuscript was approved by all authors in its form and that no competing interest exists.

Affiliation and Correspondence: ${ }^{1}$ College of Medicine and Health Sciences, School of Public Health, Hawassa University, Hawassa, Ethiopia

${ }^{2}$ Hawassa Health Department, Maternal and Child Health Officer, Hawassa, Ethiopia ${ }^{3}$ College of Medicine and Health sciences, Department of midwifery, Hawassa University, hawassa, Ethiopia

*Email:muntasha205@gmail.com
}

\begin{abstract}
BACKGROUND: Prevalence of optimal complementary feeding practices are lower than expected. Undernutrition contributes 35\% of children mortality. Our study was aimed to assess magnitude and factors associated with optimal complementary feeding practices among children 6-23 months in Bensa Dstrict, Sidama Zone, South Ethiopia, 2016.

METHOD: A community based cross sectional study was conducted from January to February 2016 in (8) randomly selected kebles found in Bensa District. Respondents were selected by using simple random sampling technique after sampling frame was prepared from rapid survey. Pre-tested questionnaire was used to collect information. Then, data were entered into SPSS version 20, Then, crude odds ratio (COR) and adjusted odds ratio (AOR) with 95\% confidence interval were computed to examine statistical significance.

RESULT: This study revealed that only $8.6 \%$ (95\%CI: 6.4, 10.7\%) of 6-23 months children had optimal complementary feeding practices. Mother's knowledge on optimal complementary feeding (AOR=5.4, 95\%CI: 2.7, 11), postnatal care service utilization $(A O R=3.4,95 \% C I: 1.7,7)$, and household food security $(A O R=5$, 95\%CI: $2.5,10.5)$ were positively associated with optimal complementary feeding practices.

CONCLUSION: Mother's knowledge, postnatal care utilization and household food security positively affected optimal complementary feeding practices.Thus, Bensa District Health Office, Sidama Zone Health Departiment and other respective stakeholders should cooperatively work to enhance knowledge of mothers/care takers on optimal complementary feeding practices, household food security and on advantages of postnatal care service utilization.
\end{abstract}

KEYWORDS: Complementary, feeding, optimal

\section{INTRODUCTION}

Globally, 5.9 million under-five children's deaths occur annually; of which $50 \%$ deaths were causeddirectly or indirectly by malnutrition. Inappropriate complementary feeding practices are considered to be the leading cause of malnutrition (2). 
Based on well-established evidences, the World Health Organization and UNICEF recommended optimal complementary feeding starting from 6 months of life. Introduction of complementary feeding at six months, minimum meal frequency, minimum dietary diversity and minimum acceptable diet are recommended components for optimal complementary feeding (3). The Ethiopian Federal Ministry of Health also developed its own IYCF recommendation guide in line with WHO's recommendations but with some modifications for the country's context (4).

In Ethiopia, complementary food is not introduced in timely fashion for all children, and about $50 \%$ children received complementary food at 6-9 months. Though this much children were introduced to solid/semisolid/soft food at 6-9 months of life, the proportion of children with minimum acceptable diet were only $4 \%$ (12). This indicates that even if more than half of the children were introduced to complementary feeding, they were given food with lower quality (non-diversified) and inappropriate frequency. On the other hand, the proportion of children with stunting, underweight and wasting were $40 \%, 29 \%$ and $9 \%$ respectively (5).

In Sidama, the proportion of mothers who initiate complementary food timely was $72.2 \%$. However, the proportion of children who got minimum acceptable diet was only $10.9 \%$ ( 7). Bensa District is one of the districts in Sidama Zone and has higher prevalence of sever and acute malnutrition (9.6\%) (8). Therefore, our study was aimed to assess the magnitude of optimal complementary feeding practices and associated factors by using core indicators of complementary feeding practices in Bensa District, Sidama Zone South Ethiopia, 2016.

\section{METHODS AND MATERIALS}

Study area and period: Bensa District is one of the 19 districts found in Sidama Zone, SNNPR State. It is located $135 \mathrm{~km}$ far from Hawassa, the capital city of SNNPR. The district is bordered with Oromiya Region in the North, Aroressa District in the South, Chire District in the East and
Arbegona and Bona Districts in the West. It is divided into 37 lowest administrative clusters/kebeles. Its total area is estimated to be $551.2 \mathrm{~km}^{2}$ and is considered as one of the densely populated districts in the zone (525 people $/ \mathrm{km}^{2}$ ).

The total population of the district is estimated to be 315,122 of whom $51.3 \%$ are females and $15.6 \%$ children below five years. The majority of the peoples are agriculture dependant, and 'kocho' is the staple food in the area. Regarding health service coverage, Primary health coverage reached $96 \%$. One primary hospital, 11 health centers, 37 health posts and 3 private medium clinics.

Study population: The study populations were mothers/caretakers having 6-23 months children from randomly selected kebeles and living in the study area for at least 6 months.

Inclusion criteria: Mothers/caretakers who had a child aged 6-23 months and lived in the study area for at least six months were included in the study.

Exclusion criteria: Mothers/caretakers who had mental illness and those who were seriously ill and cound not communicate during data collection period were excluded from the study. Again, mothers/caretakers who were not found in the house after three visits were not included.

\section{Operational definition}

Optimal complementary feeding: is proportion of both breastfed and non-breastfed 6-23 months children who started complementary feeding timely with minimum dietary diversity and minimum meal frequency to that specific age.

Timely initiation of complementary feeding: is proportion of 6-23 months children who started complementary feedings at 6 of months of life.

Minimum dietary diversity: Proportion of 6-23 months children who received at least four food groups from total of seven food groups during past the 24 hours.

Minimum acceptable diet: proportion of both breastfed and non-breast fed aged 6-23 months children who received a food with minimum dietary diversity and minimum meal frequency and for non-breastfed children, having at least minimum diet diversity (without including milk 
feed) and minimum meal frequency during the previous day.

Health development army (HDA): is a way of organizing people, disseminating information and bringing behavioral change across a community.

House hold food security: is availability and accessibility of sufficient food in the house which meets their dietary needs and preference.

Study design and sample size determination: A community based cross sectional study was conducted from January to February 2016. Sample size ' $n$ ' was determined by using single population proportion formula with the following assumptions:

Sampling procedure: Bensa District was purposely selected to assess the magnitude and the factors associated with optimal complementary feeding because of high prevalence of sever acute malnutrition prevalence. The district has 17 rural kebeles of which 8 kebeles were selected by using simple random sampling technique. After kebeles were selected, house hold folders obtained from health extension worker were checked for update to prepare sampling frame. However, they were found not updated, and hence rapid survey was conducted in those eight kebeles by using health extension workers for one week 2654 children aged 6-23 months were registered. Then, the number of the study participants was allocated for each kebele based on proportion to their population size. Finally, each study participant was selected by using simple random sampling technique after giving unique code to all.

Data collection: Data collection tool (questionnaire) was adapted from different sources $(5,9,10)$. The questionnaire was prepared in English language first and then translated into local language 'Sidaamuafoo' and again backtranslated into English by language experts to ensure consistency.

Pretest was conducted on $5 \%$ of the total sample .Eight diploma midwives' and 2 BSc health professionals, who can speak, read and write 'Sidaamuafoo' were used to collect data from the study participants.

Data quality control: Data quality was assured by using properly designed, structured, interviewer administered and pretested questionnaire. A oneday training was given to data collectors and supervisors on the objective and importance of the study before data collection. Selected data collectors and supervisors can communicate local language perfectly.

Data analysis: First, data was checked for completeness and consistency. Complete and consistent data was coded and entered into SPSS version 20 and analyzed by using the same software. Frequency distribution and percentages were computed to describe socio-demographic and other characteristics of respondents and presented in tables and figures. First, logistic regression analysis was done for selected variable. Then, from bivariate analysis output table, variables with p-value $<0.25$ selected for futher analysis. Finally, multivariate logistic regression analysis was done to identify significant association between variables and to control effects of confounder.

Ethical considerations: Ethical approval and clearance was obtained from Hawassa University, College of Medicine and Health Sciences Institution Review Board (IRB). Then, permission letter was written by the University to Bensa District administration and health offices.

Similarly, permission letter was written to the administration offices of kebeles which were included for data collection by district administration office. Informed verbal consent was obtained from all respondents .Respondents' right was reserved to refuse or stop whenever they felt inconvenience to respond. Confidentiality of respondents was kept for anything that they did not want to expose.

\section{RESULTS}

Socio-demographic characteristics of the respondents: A total 675 women were involved in the study giving a response rate of $98.1 \%$. The mean age of the respondents was $27( \pm 4.9 \mathrm{SD})$ and the majority of them, 644(97.3\%), were married with average family size of $5.11( \pm 1.9 \mathrm{SD})$. Concerning households food security, 318(48.2\%) households were food secured while the rest were food insecure with different severity: mildly insecure, 173(26.2\%), moderately insecure, 
123(18.6\%), and severely insecure, 48 (7.3\%) (Table 1).

Table 1: Socio-demographic characteristics of respondents, Bensa District, Sidama zone, South Ethiopia, 2016.

\begin{tabular}{|c|c|c|}
\hline Variable $(\mathrm{n}=662)$ & Number & $\%$ \\
\hline \multicolumn{3}{|c|}{ Age category of the respondents } \\
\hline$><20$ years & & \\
\hline$>$ 20-24years & 207 & $31.3 \%$ \\
\hline \multirow[t]{2}{*}{$>$ 25-29years } & 372 & $56.2 \%$ \\
\hline & 83 & $12.5 \%$ \\
\hline \multicolumn{3}{|l|}{ Marital status } \\
\hline$>$ Married & 644 & $97.3 \%$ \\
\hline$>$ Not in union & 18 & $2.7 \%$ \\
\hline \multicolumn{3}{|l|}{ Respondent relation to child } \\
\hline$>$ Biological mother & 650 & $98.2 \%$ \\
\hline$>$ Care taker & 12 & $1.8 \%$ \\
\hline \multicolumn{3}{|l|}{ Respondent educational status } \\
\hline$>$ Illiterate & 522 & $78.9 \%$ \\
\hline$>$ Primary school & 108 & $16.3 \%$ \\
\hline$>$ Secondary school & 32 & $4.8 \%$ \\
\hline \multicolumn{3}{|l|}{ Family size } \\
\hline$>\leq 5$ & 425 & $64.2 \%$ \\
\hline$>>5$ & 237 & $35.8 \%$ \\
\hline \multicolumn{3}{|l|}{ Religion } \\
\hline$>$ Protestant & 641 & $96.8 \%$ \\
\hline$>$ Muslim & 21 & $3.2 \%$ \\
\hline \multicolumn{3}{|l|}{ Respondent occupation } \\
\hline$>$ House wife & 621 & $93.8 \%$ \\
\hline$>$ Day laborer & 41 & $6.2 \%$ \\
\hline \multicolumn{3}{|l|}{ Husband occupation } \\
\hline$>$ Farmer & 608 & $91.8 \%$ \\
\hline$>$ Day laborer & 54 & $8.2 \%$ \\
\hline \multicolumn{3}{|l|}{ Husband education } \\
\hline$>$ Illiterate & 554 & $83.7 \%$ \\
\hline$>$ Primary school & 75 & $11.3 \%$ \\
\hline$>$ Secondary school & 33 & $5 \%$ \\
\hline \multicolumn{3}{|l|}{ Respondents wealth quintile } \\
\hline$>$ Lowest & 131 & $19.8 \%$ \\
\hline$>$ Second & 134 & $20.2 \%$ \\
\hline$>$ Middle & 133 & $20.1 \%$ \\
\hline$>$ Fourth & 131 & $19.8 \%$ \\
\hline$>$ Highest & 133 & $20.1 \%$ \\
\hline
\end{tabular}

Obstetric characteristics of respondents: Five hundred thirty-nine $(81.4 \%)$ mothers from total respondents had had antenatal care follow-up during the last pregnancy and one 191(35.4\%) of them had heard about proper child feeding during visits. Of the mothers who had attended health facilities for postnatal care visit, $186(28.1 \%)$ of had got information about proper child feeding practices from health extension workers/other health workers (Table 2).

Health service access, promotion and utilization characteristics: The majority of the respondents, $622(94 \%)$, accessed health service near to their house and three-fourth of them, 508(76\%), visited health facilities to utilize health services.

(Table 3).

Culture-related child feeding practices and power for woman decision making in the family: Two hundred twenty-eight (34.4\%) respondents believed that children must get quality food first in the family.Nevertheless, the rest majority, $434(65.6 \%)$, of the respondents respondents believed that other people like fathers, guests, mothers, and old people must get quality food first than children.

(Table 4). 
Table 2: Obstetric characteristics of the respondents, Bensa District, Sidama Zone, South Ethiopia, 2016.

\begin{tabular}{|c|c|c|}
\hline Variable & Frequency & Percentage \\
\hline \multicolumn{3}{|c|}{ Have ANC follow up during last pregnancy $(n=662)$} \\
\hline$>$ Yes & 539 & $81.4 \%$ \\
\hline$>$ No & 123 & $18.6 \%$ \\
\hline \multicolumn{3}{|c|}{ Got information about proper feeding during ANC $(\mathrm{n}=539)$} \\
\hline$>$ Yes & 191 & $35.4 \%$ \\
\hline$>$ No & 348 & $64.6 \%$ \\
\hline \multicolumn{3}{|l|}{ Place for last delivery $(\mathrm{n}=662)$} \\
\hline$>$ Home & 517 & $78.1 \%$ \\
\hline$>$ Health institution & 145 & $21.9 \%$ \\
\hline \multicolumn{3}{|l|}{ Mode of last delivery $(\mathrm{n}=662)$} \\
\hline$>$ Spontaneous vaginal & 655 & $98.9 \%$ \\
\hline$>$ Operation (c/section) & 7 & $1.1 \%$ \\
\hline \multicolumn{3}{|c|}{ Have post natal care during last birth $(n=662)$} \\
\hline$>$ Yes & 216 & $32.6 \%$ \\
\hline$>$ No & 446 & $67.4 \%$ \\
\hline \multicolumn{3}{|c|}{$\begin{array}{l}\text { Got information about proper child feeding practices during post natal care } \\
\text { follow up }(\mathrm{n}=216)\end{array}$} \\
\hline$>$ Yes & 186 & $86.1 \%$ \\
\hline$>$ No & 30 & $13.9 \%$ \\
\hline
\end{tabular}

Table 3: Health service access, promotion and service utilization characteristics of respondents Bensa District, Sidama Zone, South Ethiopia, 2016.

\begin{tabular}{|c|c|c|}
\hline Variable $(n=662)$ & Frequency & Percentage (\%) \\
\hline \multicolumn{3}{|l|}{ Child health care providing facilities available $(\mathrm{n}=662)$} \\
\hline$>$ Yes & 622 & $94 \%$ \\
\hline$>$ No & 40 & $6 \%$ \\
\hline \multicolumn{3}{|l|}{ Mother utilize health services for her child $(\mathrm{n}=662)$} \\
\hline$>$ Yes & 503 & $76 \%$ \\
\hline$>$ No & 159 & $24 \%$ \\
\hline \multicolumn{3}{|c|}{ Ever hear information about optimal complementary feeding? $(n=662)$} \\
\hline$>$ Yes & 359 & $54.2 \%$ \\
\hline$>$ No & 303 & $45.8 \%$ \\
\hline \multicolumn{3}{|l|}{ Information type ever heard: $(\mathrm{n}=359)$} \\
\hline$>$ Time of complementary feeding initiation & 255 & $71 \%$ \\
\hline$>\quad$ Minimum dietary diversity & 44 & $12 \%$ \\
\hline$>$ Minimum meal frequency & 60 & $17 \%$ \\
\hline \multicolumn{3}{|l|}{ Information source: $(\mathrm{n}=359)$} \\
\hline D Health extension workers & 282 & $78.6 \%$ \\
\hline$>$ Health workers & 45 & $12.5 \%$ \\
\hline$>$ Community members & 29 & $8.1 \%$ \\
\hline$>$ Radio & 3 & $0.8 \%$ \\
\hline \multicolumn{3}{|l|}{ Mother involved in HDA network? (n=662) } \\
\hline$>$ Yes & 270 & $40.8 \%$ \\
\hline$>$ No & 392 & $59.2 \%$ \\
\hline \multicolumn{3}{|c|}{$\begin{array}{l}\text { Have discussion about optimal complementary feeding during HDA meetings? } \\
(\mathrm{n}=270)\end{array}$} \\
\hline$>$ Yes & 125 & $46.3 \%$ \\
\hline$>$ No & 145 & $53.7 \%$ \\
\hline \multicolumn{3}{|c|}{ Respondent have knowledge about optimal complementary feeding? $(\mathrm{n}=662)$} \\
\hline$>$ Yes & 116 & $17.5 \%$ \\
\hline$>$ No & 546 & $82.5 \%$ \\
\hline
\end{tabular}

DOI: http://dx.doi.org/10.4314/ejhs.v29i2.2 
Table 4: Culture, belief and woman power to decision making in the family, Bensa District, Sidama Zone, South Ethiopia, 2016.

\begin{tabular}{lll}
\hline Variable & Frequency & Percentage (\%) \\
\hline Mother make decision about her family $(\mathrm{n}=662)$ & & \\
$>\quad$ Yes & 125 & $23 \%$ \\
$>$ No & 537 & $77 \%$ \\
Quality food given first to: $(\mathrm{n}=662)$ & 414 & $62.5 \%$ \\
$>$ Father & 20 & $3 \%$ \\
$>$ Mother & 228 & $34.4 \%$ \\
$>$ Child & & \\
Grandmothers have roles in child feeding(n=662) & 387 & $58.5 \%$ \\
$>$ Yes & 275 & $41.5 \%$ \\
No & & \\
Roles of grandmothers in child feeding:(n=387) & 254 & $65.6 \%$ \\
$>$ Counsel initiation of CF before 6months of age & 133 & $34.4 \%$ \\
$>$ Counsel initiation of CF at 6months of age & & \\
Why grandmothers counsel initiation of CF before & & \\
6months of age? $(\mathrm{n}=254)$ & 151 & $59.5 \%$ \\
$>$ Not to the child get hungry & 44 & $17.3 \%$ \\
$>$ Breast feeding consumes time & 59 & $23.2 \%$ \\
\hline Other & & \\
\hline
\end{tabular}

Complementary feeding practices among 6-23 months age children: The mean age of children was $13.78 \pm 5.17$ (SD) months. Only 217 (34\%) children started complementary feeding timly. The rest majority $(62.2 \%)$ got complementary feeding before 6 months $(22 \%)$ and after 6months (44\%) of life. (Table 5).

Dietary diversity: Regarding consumption of diversified diet, only 130(20.4\%) children ate at least four of seven food groups recommended by the World Health Oganization prior to 24 to this interview.

\section{Components of optimal complementary} feeding: Among 637 children who started complementary feeding at any age (both breastfed and non-breastfed), 339(53.2\%) had appropriate minimum meal frequency, $102(16 \%)$ had acceptable diet (both frequent and diversified diet) and 55(8.6\%) had optimal complementary feeding practices.

Factors associated with optimal complementary feeding: After descriptive analysis was done for all the variables included in the study, twenty variables were selected for bivariate logistic regression analysis. Variables with p-value $<0.25$ during bivariate logistic regression analysis were considered as candidates for multivariate logistic regression analysis. Before proceeding to multivariate logistic regression analysis for the candidate variables, multico-linearity was checked by doing co-linearity diagnostic tests and the variables with 'variance inflation factor' (VIF) below 10 were selected for final model (multivariate logistic regression) analysis to identify factors which had significant association with the dependent variable. 
Table 5: Complementary feeding practices among children aged 6-23 months, Bensa District, Sidama Zone, South Ethiopia, 2016

\begin{tabular}{|c|c|c|c|}
\hline Variable & Frequency & $\begin{array}{l}\text { Percentage } \\
\text { (\%) }\end{array}$ & Remark \\
\hline Children age category $(\mathrm{n}=662) 6-11$ months & 232 & $35 \%$ & Mean age \\
\hline$>12-17$ months & 259 & $39 \%$ & $13.8 \pm 5.2 \mathrm{Sd}$ \\
\hline $18-23$ months & 171 & $26 \%$ & months \\
\hline \multicolumn{4}{|l|}{ Child started complementary feeding $(\mathrm{n}=662)$} \\
\hline$>\mathrm{Yes}$ & 637 & $96 \%$ & \\
\hline$>\mathrm{No}$ & 25 & $4 \%$ & \\
\hline \multicolumn{4}{|l|}{ Age of complementary feeding started $(n=637)$} \\
\hline Before 6 months & 139 & $22 \%$ & \\
\hline$>$ At 6 months & 217 & $34 \%$ & \\
\hline$>$ After 6 months & 281 & $44 \%$ & \\
\hline \multicolumn{4}{|c|}{$\begin{array}{l}\text { Breast feeding continued after complementary feeding started } \\
(\mathrm{n}=637)\end{array}$} \\
\hline$>$ Yes & 604 & $95 \%$ & \\
\hline$>\mathrm{No}$ & 33 & $5 \%$ & \\
\hline \multicolumn{4}{|l|}{ Type of complementary food started $(n=637)$} \\
\hline$>$ Cow milk & 274 & $43 \%$ & \\
\hline$>$ Soft porridge made of corn floor & 296 & $47 \%$ & \\
\hline$>$ Adult food & 41 & $6 \%$ & \\
\hline$>$ Other & 26 & $4 \%$ & \\
\hline \multicolumn{4}{|l|}{ Mother include snakes between meals $(\mathrm{n}=637)$} \\
\hline$>$ Yes & 504 & $79 \%$ & \\
\hline$>\mathrm{No}$ & 133 & $21 \%$ & \\
\hline \multicolumn{4}{|l|}{ Respondent use separate container to feed her child $(n=637)$} \\
\hline$>$ Yes & 564 & $88.5 \%$ & \\
\hline$>\mathrm{No}$ & 73 & $11.5 \%$ & \\
\hline \multicolumn{4}{|l|}{ Type of container used to feed child $(n=564)$} \\
\hline$>$ Bottle & 165 & $29 \%$ & \\
\hline$>$ Cup & 161 & $29 \%$ & \\
\hline$>$ Cup with spoon & 238 & $42 \%$ & \\
\hline \multicolumn{4}{|c|}{$\begin{array}{l}\text { Respondents wash their hands before food preparation and } \\
\text { feeding of their children }(n=637)\end{array}$} \\
\hline$>\mathrm{Yes}$ & 616 & $97 \%$ & \\
\hline$>\mathrm{No}$ & 21 & $3 \%$ & \\
\hline \multicolumn{4}{|c|}{$\begin{array}{l}\text { Respondents increase feeding frequency to their children during } \\
\text { and after illness }(n=637)\end{array}$} \\
\hline$>$ Yes & 600 & $94 \%$ & \\
\hline$>\mathrm{No}$ & 37 & $6 \%$ & \\
\hline
\end{tabular}

After controlling for confounders, family size, PNC follow-ups during last birth, having knowledge about optimal complementary feeding, participation in health development army (HDA), household food security and wealth status showed significant associations with optimal complementary feeding during multivariate logistic regression.

Children from family size of five or less were 3.3(AOR $=3.3 ; 95 \%$ CI: $1.62,6.83 ; \mathrm{P}=0.001)$ times more likely to receive optimal complementary feeding as compared to those who were from

DOI: http://dx.doi.org/10.4314/ejhs.v29i2.2 
family size greater than five. Similarly, odds of providing optimal complementary feeding of respondents to their children were $3.4(\mathrm{AOR}=3.4$; 95\% CI: $1.7,7 ; \mathrm{P}=0.001$ ) times higher among mothers who had postnatal care during last birth than their counterparts.

The study revealed that children whose mothers had involved in HDA were 3.4(AOR=3.4; 95\% CI: $1.6,6.9 ; \mathrm{P}=0.001)$ times more likely to give optimal complementary feeding as compared to their counterparts. Mothers who had knowledge about optimal complementary feeding 5.4(AOR=5.4; 95\%CI: 2.7, 11; $\mathrm{P}<0.001)$ times more likely fed their children optimally as compared to not knowledgeable mothers (Table $6)$.

Table 6: Factors associated with optimal complementary feeding, Bensa District, Sidama Zone, South Ethiopia 2016

\begin{tabular}{|c|c|c|c|c|c|}
\hline \multirow[t]{2}{*}{ Variable } & \multirow[t]{2}{*}{ Response } & \multirow{2}{*}{$\begin{array}{l}\text { Have } \\
\text { practice }\end{array}$} & \multirow{2}{*}{$\begin{array}{l}\text { OCF } \\
\text { No } \\
\end{array}$} & \multicolumn{2}{|l|}{ OR(95\%CI) } \\
\hline & & & & COR & AOR \\
\hline \multirow[t]{2}{*}{ Respondent occupation } & $\mathrm{H} /$ wife & 46 & 575 & $3.5(1.6,7.8)^{*}$ & $1.7(0.55,5.27)$ \\
\hline & Other & 9 & 32 & 1.00 & 1.00 \\
\hline \multirow[t]{2}{*}{ Family size } & $\leq 5$ & 34 & 391 & $2.9(1 \cdot 6,5 \cdot 1)^{* * *}$ & $3.3(1.62,6.83)^{* *}$ \\
\hline & $>5$ & 21 & 216 & 1.00 & 1.00 \\
\hline \multirow{2}{*}{$\begin{array}{l}\text { ANC during last } \\
\text { pregnancy }\end{array}$} & Yes & 48 & 491 & $3.9(2.2,6.9)^{* * *}$ & $1.85(0.87,3.93)$ \\
\hline & No & 7 & 116 & 1.00 & 1.00 \\
\hline \multirow[t]{2}{*}{ PNC during last birth } & Yes & 35 & 181 & $4.12(2.3,7)^{* * *}$ & $3.4(1.7,7) * *$ \\
\hline & No & 20 & 426 & 1.00 & 1.00 \\
\hline \multirow[t]{2}{*}{ Health services utilization } & Yes & 49 & 454 & $2.75(1.16,6.55)^{*}$ & $0.7(0.2,2)$ \\
\hline & No & 6 & 153 & 1.00 & 1.00 \\
\hline \multirow[t]{2}{*}{ Had knowledge on OCF } & Yes & 34 & 84 & $10.4(5.7,17.7)^{* * *}$ & $5.4(2.7,11)^{* * *}$ \\
\hline & No & 21 & 523 & 1.00 & 1.00 \\
\hline \multirow{2}{*}{$\begin{array}{l}\text { Had power to Make } \\
\text { decision }\end{array}$} & yes & 28 & 93 & $4(2.3,7.1)^{* * *}$ & $1.8(0.8,3.9)$ \\
\hline & no & 27 & 514 & 1.00 & 1.00 \\
\hline \multirow[t]{2}{*}{ Participate in HDA } & Yes & 32 & 238 & $7.7(4.3,13.7)^{* * *}$ & $3.4(1.6,6.9)^{* *}$ \\
\hline & No & 23 & 369 & 1.00 & 1.00 \\
\hline \multirow[t]{2}{*}{ Household food security } & Secured & 44 & 67 & $6.6(3.7,11.7)^{* * *}$ & $5(2.5,10.5)^{* * *}$ \\
\hline & Unsecured & 11 & 540 & 1.00 & 1.00 \\
\hline \multirow[t]{3}{*}{ Wealth index } & Lowest & 6 & 127 & 1.00 & 1.00 \\
\hline & Medium & 16 & 248 & $1.4(0.5,3.6)$ & \\
\hline & Highest & 33 & 231 & $3(1.2,7)^{*}$ & $3(1.1,9)^{*}$ \\
\hline
\end{tabular}

Where: $(*) \mathrm{p}<0.05,(* *) \mathrm{p}<0.01$ and $(* * *) \mathrm{p}<0.001$ 


\section{DISCUSTION}

The result of this study showed that the magnitude of optimal complementary feeding was only $8.6 \%$ (95\%CI: $6.4,10.7 \%)$ in the studied district. This was relatively higher compared to national level and southern region proportions of acceptable diet, $4 \%$ and $3.1 \%$ respectively (5). This finding is also relatively similar with findings from rural community of Sidama (Southern Ethiopia) $(14.4 \%)$ (11), Mekele (Northern Ethiopia) $(10.75 \%)$ (12), rural community of Eastern Ethiopia (11.1\%) (13) and rural area of Northern Ghana (15.7\%) (14). Low OCF prevalence might be due to the fact that health professionals gave attention only to timely initiation of complementary feeding during nutrition promotion neglecting other optimal complementary feeding components and low maternal knowledge about optimal complementary feeding.

About $34 \%$ children had started complementary feeding at six months as recommended, but about two-third of the children either not yet started complementary feeding or started complementary feeding before or after six months of age. The proportion of children who started complementary feeding at six months in this district were lower than the national prevalence of Ethiopia (51\%) (5), Mekele (Northern Ethiopia) (80\%) (11), Kamba District (Southwest Ethiopia) (62.8\%) (15), Hiwot Fana Specialized Hospital (Eastern Ethiopia) (60.5\%) (16), Sri Lanka (75.5\%), Nigeria (58.2\%), Mumbai in India (41\%) and Madhya Pradesh, India (51.1\%) (17-20). Low prevalence of timely initiation of complementary feeding might be due to poor maternal knowledge about time of initiation for complementary feeding.

In this investigation, prevalence of minimum meal frequency for both breastfed and nonbreastfed children was $53.2 \%$. This was slightly higher than the national prevalence of Ethiopia (48.5\%) (13), Northern Ethiopia (40\%) (11), Mumbai in India (43\%) (51), Meerut (43.4\%) (53) and East Delhi (48.6\%) (21), but lower than the findings from Madhya Pradesh- India (67.8\%) (20), Nepal (76.6\%) (22) and Nigeria (56\%) (23).
This showed that almost half percentage of children were not getting complementary feeding with minimum meal frequency as per WHO's recommendation.

This study witnessed that the level of minimum dietary diversity was $20.4 \%$, which was higher compared to the national prevalence of Ethiopia (4.8\%), Southern Nations, Nationalities and Peoples Regional State (3.8\%)(5), Mekele (17\%) (11) and Mumbai-India (13\%)(19), but lower than findings from Meerut (79.6\%)(53), different areas of India like Rural India-Madhya Pradesh (47.8\%)(20), East Delhi (32.6\%)(18), Northern India (29.6\%)(21), Nepalese (30.4\%) (23) and Bangladesh (25.3\%) (20). Low maternal literacy, poor dietary diversity promotion activities and poor socio-economic status of the family might have played important roles for the low prevalence of dietary diversity in this district.

One hundred two (16\%) children received acceptable diet. This prevalence was lower compared to findings from Bangladesh (41.6\%) (20), Northern India, (37.7\%) (19), Madhya Pradesh-India (32.8\%)(20) and Nepal (26.5\%) (21). However,it was higher compared to the national prevalence of Ethiopia (4.1\%) and Southern Nations, Nationalities and Peoples Regional State of Ethiopia (3.1\%) (13),Wolayita $(3.3 \%)(17)$, Meruut (5\%) (19), Nigeria (9\%) (23), Northern Ethiopia (Mekele Town) (11.9\%) (26) and Delhi Hospital-India (13.3\%) (22). Low prevalence of minimum acceptable diet might be due to lower economic status of the family, higher family size, poor maternal knowledge about optimal complementary feeding, poor maternal postnatal care visit and poor nutrition promotion practices.

The study showed that having postnatal care service follow-up was significantly associated with optimal complementary feeding practices. This result was supported by the findings from Arab Emirates (16), Northern Ethiopia (Mekele) (11), Southwest Ethiopia (17) and Harar (18). This might indicate that information provision about optimal complementary feeding during postnatal care follow-up favor proper child feeding.

Mothers with family size less than or equal to five were 3.3 times more likely to feed their

DOI: http://dx.doi.org/10.4314/ejhs.v29i2.2 
children optimally than mothers with family size greater than five $(\mathrm{P}=0.001)$. This was supported by the finding from India (14). This might be due to the fact that a family with smaller family size better access/afford quality food timely and frequently to their children than a family with larger family size.

Maternal knowledge on complementary feeding practices showed significant association with optimal complementary feeding practices $(\mathrm{P}<0.001$.This was supported by the findings from Southern Ethiopia (Arbaminch) (15), Eastern Ethiopia (18) and East Delhi-India (23). This might indicate that presence of health extension workers in the community and nutrition promotion during provision of different health services increased maternal knowledge and impacted optimal complementary feeding practices.

Children from highest wealth quintile family better received optimal complementary feeding compared to children from poorest wealth quintile family $(\mathrm{P}=0.035)$. This was supported by the findings from Somali (15). This might indicate that there was unequal distribution of wealth, living standard and child feeding practice in the district.

This study revealed that children from food secured family/household received optimal complementary feeding compared to children from food unsecured secured families $(\mathrm{P}<0.001)$. This was similar with findings from formative assessment done by Concern Ethiopia in Northern Ethiopia (5). This might indicate that inaccessibility of food in the household could hamper optimal complimentary feeding practices.

Maternal participation in health development army showed significant positive association with optimal complementary feeding practices $(\mathrm{P}=0.001)$. This might be due to the fact that active participation in the network helped to increase maternal knowledge about optimal complementary feeding and increase health seeking behavior of mothers to keep their family healthy.

Children from the highest wealth quintile family received optimal complementary food 3 (AOR=3; 95\%CI: 1.1, 9; $\mathrm{P}=0.035)$ times more likely compared to children from medium wealth status family. Similarly, children from food secure family got optimal commentary food $5(\mathrm{AOR}=5$; 95\% CI: $2.5,10.5, \mathrm{P}<0.001)$ times more likely compared to children from food secured households.

Only $8.6 \%(95 \%$ CI:6.4,10.7) children aged 623 months got optimal complementary feeding with considering timely initiation of complementary feeding, minimum meal frequency and minimum dietary diversity as its components in this district. The rest majority (nine out of ten ten) of children had sub-optimal complementary feeding practice in the area which would have negative effects on the health of infants and young children. This particular study indicated that immediate action needs to be taken to promote optimal complementary feeding.

The study identified some important factors like family size less than or equal to five, maternal knowledge, postnatal care follow-up, maternal involvement in health development army, house hold food security and highest wealth status can increase optimal complementary feeding practice. Based on the findings, the following points are recommended:

$>$ The health professionals' need to strengthen promotion of timely initiation of complementary feeding considering minimum meal frequency and minimum dietary diversity.

$>$ Focus on family planning to limit family size and then to improve children feeding practices.

$>$ Strengthen optimal child feeding practices promotion and counseling to mothers during postnatal care service visits.

\section{ACKNOWLEDGMENTS}

Above all, we would like to thank almighty God for all the things he made favorable for me. Our thank goes to Sidama Zone Health Department Nutrition pin point officers and Bensa District Health Office head and all staffs for the commitment they made in every direction for the success of this work. Again,we acknowledge Hawassa City Administration Health Department 
and Alamura Health Center for material and morale support. Lastly, we would like to thank all data collectors, supervisors, Bensa Dstrict health extension workers, respondents and all others involved/contributed in this work even indirectly.

\section{REFERENCES}

1. Alex-Hart BA, Opara PI. Infant and young child feeding practices in three communities of Obio Akpor, Nigeria. Journal of applied medical sciences. 2015; 3(1B):100-104.

2. World health organization. Infant and young child feeding, model chapter for medical students and allied health professionals, 2009.

3. Ethiopia federal ministry of health. Infant and young child feeding quick reference book. Ethiopia, 2010.

4. Ethiopian Demographic and Health Survey. Central statistics agency. Addis Ababa, 2011.

5. Ethiopian min Demographic and Health Survey .Central Statistics Agency. Addis Ababa, 2014.

6. Sidama Zone Health Department annual report on outpatient therapeutic program. Hawassa, 2015.

7. USAID, report on nutrition and retrospective mortality survey conducted in Bensa district, Sidama Zone, Southern region. June 2015.

8. Food and nutrition assistance (FANTA). House hold dietary diversity score (HDDS) for measurement of households food access. Indicator guideline. September 2006, version 2.

9. Household food insecurity access scale (HHFIAS) for measurement of food access. August, 2007, version 3.

10. Tessema M, Belachew T and Ersino G. Feeding patterns and stunting during early child hood in rural communities of Sidama. Pan African edical journal.2013;14(75).

DOI: $10.11604 /$ pamj.2013.14.75.1630

11. Mekibib E, Shumey A, Ferede S and Haile F. Magnitude and Factors Associated with Appropriate Complementary Feeding among Mothers Having Children 6-23 Months-ofAge in Northern Ethiopia; A CommunityBased Cross-Sectional Study. Journal of Food and Nutrition Sciences. 2014: 2,36-42.
12. Mahama Saaka, Anthony Wemakor, AbdulRazak Abizari and Paul Aryee.How well WHO complementary feeding indicators relate to nutritional status of children aged 623 months in rural Northern Ghana.BMC Public health.2015; Volume 15, Number 1157.

13. Kedir Tej Roba,Thomas P.O' Connor, Tefera Belachew,Nora M.O'Brien. Infant and young child feeding practices among mothers of children aged 6-23 months in two agro ecological zone of rural Ethiopia.International journal of nutrition and food sciences.2016;5 (3):185-194.

14. Agedew E, Demissie M,Misker D and Haftu D. Early Initiation of Complementary Feeding and Associated Factors among 6 Months to 2 Years Young Children in Kamba Woreda, South West Ethiopia. Journal of Nutrition Food Science.2014;4(5):314.

15. Agumasie S, Gezahegn $\mathrm{T}$ and Alemayehu B. Complementary feeding practices of mothers and associated factors in Hiwot Fana Specialized hospital, Harari town Eastern Ethiopia. Pan African medical journal. 2014; 18:143.

16. Nishani H. Ubeysekera, Renuka Jayathissa, Champa J.Wijesinghe. Nutritional status and associated feeding practices among children age 6-23 months in a selected community in Sri Lanka. European journal of preventive medicine. 2015; 3:15-23.

17. Umar M. Gboluwaga T. Amole,Mahmud G.jahum,Abdullah Sani. Age appropriate feeding practice $s$ and nutritional status of infants attending child welfare clinic at a teaching hospital in Nigeria. Journal of family and community medicine. April 2014;21(1):612.

18. Abigail Bentley, Shushmita Das, Glyn Alcock, Neena Shah more,Shanti Pantvaidya and David Osrin. Malnutrition and infant and young child feeding in informal settlements in Mumbai. Food science and nutrition. 2015; 3(3): 257-271.

19. Swati Jain, Amod Borle, Sanjays Agrawal, Mahesh Kumar Mishra, Sanjah Kumar Gupta and Vishal Bathma.Assessment of infant and 
young child feeding practice in rural Madhya Pradesh - India. National journal of community medicine.2014; 5(4): 419-423.

20. Amir Maroof Khan, Priscilla Kayina, Paras Agrawal, Anita Gupta, Anjur Tupil Kannan.Study on infant and young child feeding practices among mothers attending an urban health center in east Delhi -India. Indian journal of public health; 2012;56(4):302-304.
21. Vishnu Khanal, Kay Sauer, Yun Zhao. Determinants of complementary feeding practices in Nepal children aged 6-23 months: Findings from demographic and health survey. BMC pediatric journal. 2013:13:131.

22. Felix A Ogbo, Andrew Page, John Idoko. Trends in complementary feeding in Nigeria 2003-2013. BMJ, 2015:5(10):1-12. 